Revista de Comunicación y Salud, 2018, Vol. 8, nº 2, pp. 5-19

Editado por Cátedra de Comunicación y Salud

ISSN: 2173-1675

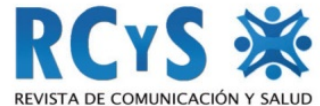

Enviado 01 de octubre de 2018

Aprobado 4 de julio de 2018

\title{
ROSTROS MESTIZOS: UNA PROPUESTA COMUNICACIONAL PARA EL ESTUDIO DE ITINERARIOS TERAPÉUTICOS ANCESTRALES EN LATINOAMÉRICA ${ }^{1}$
}

\author{
Mestizo faces: a communication proposal for the study of ancestral therapeutic \\ itineraries in Latin America \\ Vanina Belén Canavire ${ }^{2}$ \\ CONICET. Argentina
}

\begin{abstract}
Resumen
En un contexto de medicalización de la vida cotidiana y disciplinamiento de los cuerpos, se torna apremiante preguntarnos qué ocurre con las percepciones colectivas y las prácticas en salud, particularmente en las poblaciones latinoamericanas con culturas sanitarias ancestrales. En este marco, aquí proponemos el análisis de las representaciones sociales sobre los "itinerarios terapéuticos locales", desde la mirada disciplinar de la Comunicación Social, en tanto espacio simbólico donde se generan los procesos de producción y circulación de significaciones sociales. Para ello, ponemos a consideración tres argumentos. El primero presenta al subcampo de la Comunicación y Salud, y las problemáticas que allí convergen. Bajo ese marco teórico, abordamos a la Salud intercultural y a la Comunicación para el cambio social como posibles herramientas intelectuales para reflexionar sobre las distintas "maneras de curar". El segundo argumento refiere a la posibilidad de pensar a los discursos en torno a los conocimientos y recursos terapéuticos tradicionales, como parte del patrimonio cultural intangible de una población. Atendiendo a los conflictos que conllevan los procesos de patrimonialización, es central que se busque abordar los patrimonios locales en toda su complejidad, lejos de miradas escencializantes que hacen de la diversidad una exotización. El tercero plantea la necesidad de indagar en las formas particulares convivencia, mixtura, invisibilización- que adopta la articulación entre los saberes locales ancestrales y los saberes vinculados a prácticas terapéuticas funcionales a la globalización cultural. Sin dudas, el estudio de los discursos, narrativas y procesos de construcción social de la salud puede revelar uno de los tantos rostros mestizos que delinea la interacción entre lo local y lo global.
\end{abstract}

\footnotetext{
${ }^{1}$ Artículo de reflexión realizado en el marco de mis tareas como investigadora de CONICET (Argentina), dentro de la línea "Comunicación y Cultura". El trabajo se enmarca en el proyecto "Puesta en valor de bienes culturales y patrimoniales en Jujuy", asentado en la Unidad Ejecutora en Ciencias Sociales Regionales y Humanidades (CONICET- Universidad Nacional de Jujuy), con financiación del Consejo Nacional de Investigaciones Científicas y Técnicas, Argentina.

${ }^{2}$ Autor para correspondencia: Vanina Belén Canavire belencanavire@hotmail.com
} 
Rostros mestizos: una propuesta comunicacional para el estudio de itinerarios terapéuticos ancestrales en Latinoamérica

Palabras clave: comunicación y salud, salud intercultural, comunicación para el cambio social, culturas sanitarias ancestrales, Latinoamérica.

\begin{abstract}
In a context of medicalization of daily life and the disciplining of bodies, it becomes urgent to ask what happens with collective perceptions and practices in health, particularly in Latin American populations with ancestral health cultures. In this framework, here we propose the analysis of social representations about "local therapeutic itineraries", from the disciplinary perspective of social communication, as a symbolic space where the processes of production and circulation of social meanings are generated. For this, we put three arguments into consideration. The first presents the subfield of Communication and Health, and the problems that converge there. Under this theoretical framework, we approach Intercultural Health and Communication for social change as possible intellectual tools to reflect on the different "ways of healing". The second argument refers to the possibility of thinking about discourses around traditional knowledge and therapeutic resources, as part of the intangible cultural heritage of a population. Attending to the conflicts that involve the processes of patrimonialization, it is essential to seek to address the local heritage in all its complexity, far from essential looks that make diversity an exoticism. The third raises the need to investigate particular forms -convival, mixture, invisibility- that the articulation between ancestral local knowledge and knowledge linked to functional therapeutic practices to cultural globalization. Undoubtedly, the study of discourses, narratives and processes of social construction of health, can reveal one of the many mestizo faces that delineates the interaction between the local and the global.
\end{abstract}

Keywords: communication and health, intercultural health, communication for social change, ancestral health cultures, Latin America.

\title{
Cómo citar el artículo
}

Canavire, V. B. (2018). Rostros mestizos: una propuesta comunicacional para el estudio de itinerarios terapéuticos ancestrales en Latinoamérica. Revista de Comunicación y Salud, 8(2), 5-19.

doi: http://doi.org/10.35669/revistadecomunicacionysalud.2018.8(2).5-19

\section{INTRODUCCIÓN}

La cordillera de los Andes, con sus cerca de $8.000 \mathrm{~km}$ de recorrido, se extiende desde la costa del Caribe de Colombia, por el norte, hasta el Cabo de Hornos en el sur; por el occidente emerge del Océano Pacífico, y se interna en las selvas amazónicas o se pierde cerca de las dilatadas llanuras argentinas. En paralelo con esta diversidad ambiental, las poblaciones originarias que ocuparon tan vasta área mostraban también una máxima diversidad, aunque con elementos unificadores, como por ejemplo la agricultura, dando lugar a la formación de un complejo mosaico cultural. Sobre esta población originaria se inserta hace 500 años la corriente colonizadora europea, con prácticas y saberes propios que se tratan de implantar en el Nuevo Mundo. Esta 
Rostros mestizos: una propuesta comunicacional para el estudio de itinerarios terapéuticos ancestrales en Latinoamérica

diversidad cultural y étnica caracteriza hoy a los cinco países de la región andina, y está representada por la presencia de tres grandes sectores de población: el nativo, el mestizo, el europeo o su descendiente, a los que en algunas regiones debe sumarse el afroamericano.

En este complejo panorama, los conceptos de salud y enfermedad, así como los recursos terapéuticos son también hoy en día muy diversos, y coexisten diferentes sistemas médicos, siendo los más destacables la biomedicina y la medicina tradicional. Si bien la cultura de las poblaciones latinoamericanas es muy rica, algo que las ha caracterizado a lo largo de los años, son los rituales, las creencias, y su vinculación con la naturaleza. De esta forma, la terapéutica local, se inserta en una visión de mundo propia, y constituye un elemento característico.

Como es sabido, la migración rural, el turismo, la patrimonialización, la expansión de las industrias culturales y la tecnología, la proliferación de culturas terapéuticas en distintos formatos (reiki, yoga, ayurvédica, talleres new age, etc.), entre muchos otros fenómenos, han motivado cambios en las sociedades con culturas sanitarias ancestrales. Si bien estas configuraciones culturales adquieren matices distintos según se trate de zonas rurales o urbanas, lo cierto es que se producen fenómenos de convivencia, mixtura, yuxtaposición, e invisibilización de saberes (propios y ajenos) que afectan al ámbito de la salud/enfermedad/atención.

Frente a ello, nuestro interés en este artículo gira en torno a proponer el estudio de las representaciones sociales sobre los "itinerarios terapéuticos locales", desde la mirada disciplinar de la Comunicación Social, en tanto espacio simbólico donde se generan los procesos de producción y circulación de significaciones sociales.

A partir del análisis de numerosos antecedentes, desarrollados principalmente desde la antropología y la etnobotánica, aquí sostenemos la pertinencia de incluir el estudio de las representaciones sobre la vigencia y circulación de medicinas y saberes tradicionales a un campo en construcción: el de la "Comunicación y Salud". Así, exponemos tres argumentos para sostener nuestra propuesta. El primero refiere a que la Comunicación y Salud, en tanto campo transdisciplinar y relacional, admite que allí confluyan dos enfoques que promueven el diálogo y colaboración de saberes, prácticas y demandas en salud entre actores con diferencias socioculturales: la "Salud intercultural" y la "Comunicación para el cambio social". El segundo argumento alude a que los saberes sobre "medicina tradicional", en tanto constituyentes de los procesos de construcción identitaria y cohesión social, son parte esencial del patrimonio intangible de una población, y reflexionar acerca de su valor como "bien cultural" -sin perder de vista los conflictos que acompañan a los procesos de patrimonialización- es una manera de contribuir a la recopilación de este rico bagaje ancestral. Por último, el tercer argumento plantea la posibilidad de abordar, desde una mirada comunicacional, el lugar que ocupan los itinerarios terapéuticos locales frente a la proliferación de productos y prácticas terapéuticas funcionales a la globalización cultural, a fin de acercarnos a las formas de articulación -convivencia, mixtura, invisibilización, etc.- que se producen entre estos distintos saberes. 
Rostros mestizos: una propuesta comunicacional para el estudio de itinerarios terapéuticos ancestrales en Latinoamérica

\section{COMUNICACIÓN Y SALUD: UN CAMPO TRANSDISCIPLINAR}

En las últimas dos décadas, según plantea Obregón (2010), en el campo de Comunicación y Salud en América Latina se ha pasado de la opción privilegiada de propuestas centradas en la identificación y el uso de mensajes y canales apropiados para llegar a públicos objetivo, al uso de enfoques de comunicación para el cambio de comportamiento que se apoyan en un conjunto de teorías y modelos de cambio de comportamiento individual provenientes de la psicología social y finalmente, a perspectivas de comunicación y cambio social que se nutren de propuestas conceptuales y teóricas que integran aspectos individuales, colectivos y sociales de la salud. En este sentido, el autor sostiene que lo que mejor caracteriza actualmente a nuestra región es un enfoque informado por abordajes comunicativos anclados en estas últimas perspectivas de Comunicación para el desarrollo y el cambio social, que enfatizan la necesidad de comprender la comunicación, no como instrumento o herramienta de transmisión de información, sino también como un proceso de diálogo que facilite la participación de diversos grupos sociales en la mejora de sus condiciones de salud.

Así también, entendemos que hay un consenso en la literatura sobre Comunicación y Salud en considerar que se trata de un "campo" que atraviesa un proceso de construcción académica. Para Alcalay (1999), el campo se refiere a tres cuestiones principales: es un área de investigación aplicada, tiene pertinencia social y es interdisciplinario. Por su parte, Cuberli y Araújo (2015), desde una perspectiva bourdesiana, bosquejan Comunicación y Salud como un espacio "relacional y multidimensional", y lo diferencian de otras denominaciones como Comunicación en Salud o Comunicación para la Salud, cuyas perspectivas priorizan una concepción instrumental de la comunicación "al servicio de la salud".

Aunque los especialistas en salud pública en general esperan de la comunicación saberes y herramientas útiles al logro de objetivos propios de salud (lo que explica que comunicación, educación para la salud y promoción de la salud habitualmente se confundan) desde la investigación en comunicación el interés parte de preguntas más abarcadoras que varían según las fuentes disciplinares en las que abreva (psicología, antropología, sociología, etc.) y que por supuesto también van a influenciar los modos de intervenir en lo social desde esta dimensión.

La Comunicación y Salud conforma un dominio de saber emergente construido social e históricamente que implica la convergencia de dominios disciplinares relativamente autónomos y disyuntos como la "Comunicación" y la "Salud", sin embargo, podemos pensar la Comunicación y Salud como un campo transdisciplinar.

Desde esta perspectiva, es posible plantear que los estudios de Comunicación y Salud conforman un campo vasto de problemáticas diversas, abarcando asuntos tales como las estrategias comunicacionales de políticas públicas en salud, la comunicación institucional en/de establecimientos de salud, la comunicación pública ante crisis sanitarias y los procesos comunicacionales implicados en la movilización social por 
temas de salud. Asimismo, comprende la construcción de noticias sobre temas de salud, el discurso publicitario referente a medicamentos y productos dirigidos a la salud, los discursos gubernamentales de prevención de enfermedades y promoción de hábitos saludables, y la comunicación y divulgación científica de la investigación en salud. Igualmente, son objeto de estudio el carácter comunicacional de la relación médico paciente, el tratamiento de la salud en entornos digitales y el uso de dispositivos informáticos y aplicaciones para el monitoreo y la gestión personal de la salud. Además, el acceso a información vinculada a cuestiones de salud en internet y las implicancias subjetivas e intersubjetivas de la circulación de imágenes y significaciones relativas al cuidado de la salud a través de redes sociales, entre otros.

Así mismo, y al interior de estas problemáticas, advertimos que la comunicación remite a múltiples niveles. Puede referir a un plano de comunicación interpersonal como la que se pone en juego en la relación entre médico y paciente. Por otra parte, la campaña de una política pública en salud atañe a un nivel de comunicación masiva y mediática que puede contemplar distintos soportes (gráfico, televisivo, radial, internet). Así, en algunas ocasiones se apela a la comunicación en un nivel que tiene que ver más precisamente con la información y se pretende explotarla instrumentalmente tal como si fuese una herramienta técnica. Otro nivel consiste en la comunicación social como espacio simbólico donde se generan los procesos de producción y circulación de significaciones sociales. En este nivel, la comunicación opera como una escala macro o atmósfera en la que acontecen diversos fenómenos y problemáticas micro que corresponden a los otros niveles o modos de comunicación.

Que la Comunicación y Salud sea un campo en construcción y en estado de ebullición en virtud de las dinámicas que le imprimen los procesos sociales contemporáneos permite concebirlo como un territorio modelable. En estas coordenadas, proponemos dos herramientas teóricas para pensar una problemática que involucra discursos, prácticas, consumo, rituales, capitales, sujetos individuales y colectivos. Creemos que el estudio de las representaciones sociales sobre saberes de la medicina tradicional puede incorporarse al arco teórico de la Comunicación y Salud, abordado desde: 2.1.) la "Salud intercultural" y 2.2.) la "Comunicación para el cambio social".

\subsection{Salud intercultural}

Partiendo del presupuesto de que existen múltiples concepciones de la salud y la enfermedad, y que a cada una de ellas corresponderán formas de diagnóstico y tratamiento diferenciadas, la perspectiva intercultural se revela como una herramienta de máxima utilidad y alcance para influir en el diseño de proyectos y programas de salud a la búsqueda de una mayor efectividad, y reclama la necesidad de un verdadero diálogo intercultural respetuoso con las concepciones y prácticas que comprometen al cuerpo, la salud y la enfermedad entre personas de distinta extracción sociocultural. En esta línea de pensamiento, se ubican las propuestas de investigadores que, desde diferentes miradas, definen a la salud intercultural en vinculación a la gestión sanitaria, el espacio de comunicación entre el personal de salud y el paciente, y la necesidad de articular los saberes culturales que allí intervienen. 
El médico José Baixeras Divar (2006), Director del Programa de Salud de la Agencia Española de Cooperación Internacional de La Paz (Bolivia), propone a la "Salud intercultural" como un enfoque transversal que tiene que ver particularmente con la formación sanitaria, los servicios que se prestan, los programas de salud y la gestión sanitaria. En este sentido, la Salud intercultural incluye distintas actuaciones: el auto cuidado familiar, cultural, tradicional; la acreditación y calidad en la práctica de la medicina tradicional; la adecuación cultural en los servicios de salud públicos; y la integración de la medicina tradicional en el sistema público. El autor sostiene que el mejoramiento de todos estos aspectos es el desafío que se plantea en un mundo más globalizado y a la vez más particularizado con mayor autoidentificación cultural.

Desde la antropología, en un análisis sobre programas de cooperación al desarrollo en América Latina, Montserrat Pulido Fuentes plantea la necesidad de reflexionar sobre las relaciones que se establecen entre el personal de salud y el paciente en todo tipo de situaciones, en función de que a los centros sanitarios los pacientes acuden con todo el bagaje cultural, con las preconcepciones de origen sobre la salud y la enfermedad, y con estrategias dispares de acceso a las diferentes terapias. En este sentido, define a la salud intercultural como "el proceso terapéutico, y como tal al espacio de interacción, comunicativo y de colaboración entre el que consulta y solicita ayuda para resolver un problema de salud o una situación, y el asesor, orientador o consejero al que se considera cualificado para ayudarle" (2017, p. 35). De esta forma, destaca la implicación de la diferencia cultural de los sujetos en interacción en todo ejercicio de la práctica sanitaria.

Por su parte, desde la antropología médica, Ana María Oyarce define la interculturalidad en salud como "la capacidad de moverse equilibradamente entre conocimientos, creencias y prácticas culturales diferentes respecto a la salud y la enfermedad, la vida y la muerte, el cuerpo biológico, social y relacional" (1996: 56). Se trata de un proceso social interactivo, donde se perseguiría reconocimiento y respeto a las diferencias existentes entre las culturas en el campo de la salud y la enfermedad. $O$ de otro modo, estamos ante un diálogo y colaboración en saberes, prácticas y demandas en salud entre agentes y actores con diferencias socioculturales.

En tanto, el antropólogo y médico Roberto Campos (2004) vincula la salud intercultural a la práctica y el proceso relacional que se establecen entre el personal de salud y los enfermos, donde ambos pertenecen a culturas diferentes, y de donde se requiere un recíproco entendimiento para que los resultados del contacto (consulta, intervención, consejería), sean satisfactorios para las dos partes.

Como queda reflejado, estos autores coinciden en que la Salud intercultural permite acercarse a diferentes formas de conceptualizar la salud y las aflicciones del cuerpo enfermo especialmente en contextos de complejidad intercultural. También se postula como una herramienta crítica frente al modelo biomédico hegemónico, permitiendo además revalorizar prácticas terapéuticas "tradicionales" y aportando una metodología apropiada para analizar la diversidad y abordar conceptos "otros" de salud y enfermedad. 
No obstante, también encontramos posturas críticas con respecto al discurso y a las retóricas de la interculturalidad en salud. En este sentido, se advierte el empleo del concepto como un arma política que no hace más que perpetuar el dominio del poder biomédico occidental, o su identificación con un ideal utópico que presta poca atención a la gran dificultad de articular modelos médicos diferentes y a la falta de formación en "competencias culturales" de los actores que llevan adelante los programas de salud.

La interculturalidad en salud, según Flores, se trataría habitualmente de una retórica empleada a nivel institucional por algunas agencias y fundaciones no gubernamentales, de poca utilidad en el desarrollo de programas de salud eficaces. Al respecto, señala: "es un arma política e inclusive un instrumento de continuar la dominación y control colonial de otras culturas y sociedades, en este caso por la lógica y poder biomédico occidental, enmascarado en ocasiones bajo los términos de desarrollo, cooperación, ayuda humanitaria, solidaridad, hospital" (2011, p. 8).

Por su parte, Gil García advierte:

A pesar de los esfuerzos que desde diferentes sectores se viene haciendo cada vez más por abordar los temas de salud desde una perspectiva intercultural, lo cierto es que a veces todavía resulta complicado anular esa distinción entre el 'nosotros' y el 'ellos', entre un modelo civilizado, europeo, racional, científico, biomédico, y otros que son tachados de primitivos, no europeos, no racionales, tradicionales (Gil García, 2011, p. 2).

El autor indica que la solución no pasa por reconstruir el cuerpo de los otros para desterrar de su racionalidad cultural ideas erróneas, sino de relativizar los itinerarios terapéuticos y establecer un diálogo entre las partes.

Por último, Abad (2005) considera que existe un preocupante desconocimiento sobre el concepto de Salud intercultural -inclusive en las organizaciones no gubernamentales que desarrollan proyectos de salud en contextos y poblaciones con marcada singularidad sociocultural- y plantea la necesidad de una exigencia de "competencia cultural" a las ONG, actores protagónicos de la cooperación al desarrollo y que despliegan importantes programas de salud.

De esta manera, la propuesta ideológica de la interculturalidad en el campo de la salud debe considerar al paciente, al otro, al destinatario de los cuidados, el centro de su atención, y dirigirse a él de forma dialógica, sincera y significativa, entendiendo las situaciones de contacto cultural como un encuentro intersubjetivo y el eje central del cuidado holístico.

\subsection{Comunicación para el cambio social}

La "Comunicación para el cambio social" aparece a fines del siglo como un paradigma reformulado, que rescata y profundiza el camino recorrido por la "comunicación para el desarrollo" y la "comunicación alternativa". De la primera 
corriente hereda la preocupación por la cultura y por las tradiciones comunitarias, el respeto hacia el conocimiento local, el diálogo horizontal entre los expertos del desarrollo y los sujetos del desarrollo. En tanto, con la "comunicación alternativa" comparte la premisa de que el proceso comunicacional es más importante que los productos. En vista de ello, postula que la participación de los actores sociales se da en el marco de un proceso de crecimiento colectivo anterior a la creación de mensajes o productos (un programa de radio, un video, un panfleto).

Al respecto, Gumucio Dagrón (2011) señala algunas condiciones que caracterizan a los procesos de Comunicación para el cambio social: a) Participación comunitaria y apropiación: es necesaria la participación y compromiso de los actores y sujetos del cambio; b) Lengua y pertinencia cultural: el proceso de comunicación no puede ignorar las particularidades de cada cultura y de cada lengua, por el contrario, debe apoyarse en ellas para legitimarse; c) Generación de contenidos locales: es fundamental la generación de contenidos propios, que rescaten el saber acumulado a través de las distintas generaciones; y d) Convergencias y redes: los procesos de comunicación que no establecen un diálogo más amplio con otras experiencias similares a escalas local, regional o global, tienen menos posibilidades de crecer y de ser sostenibles en el largo plazo.

La Comunicación para el cambio social rechaza el modelo lineal de transmisión de la información, y promueve un proceso cíclico de interacciones desde el conocimiento compartido por la comunidad y la acción colectiva. En este sentido, aboga por el diálogo, el debate y la participación, con el propósito de fortalecer la identidad cultural, la confianza, el compromiso, la apropiación de la palabra y el fortalecimiento comunitario.

En virtud de las premisas que la constituyen, consideramos que la Comunicación para el cambio social ofrece una perspectiva adecuada para el análisis de las representaciones sobre la vigencia y circulación de los saberes terapéuticos locales. EI énfasis puesto en la interacción cultural, en un marco de equidad y respeto, así como la revalorización del saber comunitario, resulta fundamental para abordar una problemática que reclama el respeto por el conocimiento local y el diálogo horizontal entre los actores involucrados.

\section{HUELLAS IDENTITARIAS: LA MEDICINA TRADICIONAL COMO "BIEN CULTURAL"}

En los últimos años, el patrimonio cultural se ha visto enriquecido en dos dimensiones, que han generado un verdadero cambio paradigmático en la manera de ver y entender aquello que consideramos un legado del pasado. Ese cambio ha estado motivado, en primer lugar, por la expansión del concepto de patrimonio que ha sobrepasado con creces la idea tradicional de monumentos y, en segundo lugar, por el rol político, económico y social que fue asumiendo a través de los años. Ambos aspectos han tenido un impacto considerable en la manera tradicional de investigar, conservar y administrar el patrimonio. 
A partir de los lineamientos establecidos por la Convención de la UNESCO del 2003, se han hecho enormes progresos hacia el reconocimiento del patrimonio intangible. Ello significa que no sólo debe protegerse la cultura material de una comunidad, sino además sus conocimientos ancestrales, técnicas, rituales, música, memoria oral, es decir todos aquellos aspectos intangibles de su cultura que le proveen de un sentimiento de identidad y continuidad a través del tiempo. Asimismo, se ha afirmado que el patrimonio cultural o natural no puede ser separado de su entorno social y cultural, en el sentido de que la conservación y rehabilitación de un bien patrimonial no puede hacerse en desmedro de la comunidad que habita en el lugar.

En torno a esta problemática, García Canclini (1999) hace énfasis en los usos sociales del patrimonio y lo describe en términos de un "lugar de complicidad social" que expresa la solidaridad entre quienes comparten un conjunto de bienes y prácticas que los identifica. En esta línea argumentativa, propone pensar al patrimonio en términos de capital cultural -Bourdieu-, como algo no estable, y que es apropiado por los distintos estratos de la sociedad de manera desigual.

Arévalo también destaca la función identificadora que cumple el patrimonio y lo vincula con representaciones y símbolos, "del carácter simbólico del patrimonio deriva su capacidad para representar una determinada identidad" (2004, p. 933). En este sentido, el patrimonio se define como una selección de los elementos y las manifestaciones más representativas de la realidad cultural de cada grupo social.

Por su parte, Pardo y Gómez caracterizan al patrimonio intangible como identitario y referencial, "se trata de rasgos muy significativos de la vida de la comunidad, fruto de su experiencia histórica y de sus peculiares relaciones con el medio, que contribuyen claramente a la conformación de la identidad del grupo" (2003, p. 173). Al respecto, subrayan que no se trata de bienes de gran valor económico o especialmente llamativos por su excepcionalidad, sino que su fuerza viene de su capacidad de conferir cohesión al grupo, al transmitir emociones mediante signos comprendidos por sus integrantes.

Diversos autores destacan la necesidad de analizar críticamente las implicaciones de patrimonializar las prácticas culturales, sobre todo si se piensa en un proyecto histórico que una y cohesione a los grupos sociales preocupados por la forma en que habitan su espacio y conquistan su calidad de vida.

En este sentido, se señala que la patrimonialización de las expresiones culturales con frecuencia resulta en la folclorización, mercantilización y alteración del sentido sociocultural de dichas prácticas debido a que la autoridad de las proclamaciones sigue recayendo en los actores institucionales, quienes aún poseen una visión esencialista y consensual de la cultura, impregnada de concepciones tradicionalistas (Villaseñor y Zolla, 2012). A esto se suma la existencia de contradicciones entre actores locales, "expertos" e instituciones.

Otorgar relevancia a los actores locales implica entender al patrimonio cultural a partir de los sentidos -diversos y muchas veces con versiones "en disputa"-, que les 
dan esos actores, considerando sus "intersecciones" con lo global y con otras expresiones culturales locales (Lacarrieu y Pallini, 2001). De esta manera, es central que la tarea de registro de los patrimonios locales busque abordarlos en toda su complejidad, lejos de miradas escencializantes que hacen de la diversidad una exotización y folclorizan la diferencia, la fijan, "la aquietan", al tiempo que la despolitizan y eluden el conflicto.

Finalmente, en distintos trabajos de investigación, se plantea la necesidad de repensar al patrimonio fuera de la red de conceptos en la que se halla envuelto historia, tradición, monumentos, conservación- y vincularlo con nuevas redes conceptuales: turismo, desarrollo urbano, mercantilización, comunicación masiva, etc.

A partir de un estudio sobre la valoración turística del patrimonio en Argentina, Almirón, Bertoncello y Troncoso (2006) sostienen que, si el proceso de patrimonialización en sí constituye un proceso social conflictivo, su articulación para el turismo representa una segunda instancia de conflicto. Por lo que puede ocurrir la perdida de identificación de algunos sectores de la población local con aquellos elementos legitimados como patrimonio una vez que son valorizados ( $y$ transformados para) el consumo turístico.

La actividad turística entronca directamente con el consumo, y no se trata de un consumo de objetos, sino de servicios. En esas condiciones, el patrimonio cultural se torna un servicio más que los turistas consumen: "su interés radica más en 'ver' lo que ellos 'han perdido', que en descubrir lo que realmente son o han sido las comunidades receptoras, ahora 'empaquetadas' y convertidas en producto turístico" (Martín, 2003, p. 159). En este sentido, el patrimonio se concibe como un rescate de elementos del pasado, desde las circunstancias y necesidades del presente. Para el caso de México, Villaseñor y Zolla (2012) advierten que cuando la activación patrimonial se lleva a cabo dentro de un discurso nacionalista, ésta implica necesariamente un cambio en el sentido de propiedad de las prácticas culturales, lo que potencialmente atenta contra los derechos culturales de los grupos sociales. Por otra parte, existe el riesgo de transformar las formas culturales locales en productos meramente comerciales, sujetos a las demandas de la industria turística o las necesidades de representación de los medios de comunicación masiva.

Numerosos trabajos de investigación -realizados fundamentalmente desde la antropología y la etnobotánica- describen a la "medicina tradicional" como un saber difundido y un conjunto de comportamientos socialmente compartidos, que forman parte del complejo patrimonio de conocimientos empíricos y toman sentido en relación a las condiciones materiales de existencia de una población. En coincidencia con estas propuestas teóricas, consideramos que los saberes sobre "medicina tradicional" son una parte esencial del patrimonio intangible de un grupo étnico o social, y reflexionar acerca de su valor como "bien cultural", sin perder de vista los conflictos que acompañan a los procesos de patrimonialización, es una manera de contribuir a la recopilación de este rico bagaje ancestral. 
Rostros mestizos: una propuesta comunicacional para el estudio de itinerarios terapéuticos ancestrales en Latinoamérica

\section{SABERES ANCESTRALES Y SOCIEDAD GLOBALIZADA}

La globalización alberga en su seno vertientes de homogeneización y de heterogeneidad cultural. Quienes sostienen que los efectos mayores sobre el sistema mundial son de homogeneización, enfatizan la importancia de la globalización económica a partir de la acción de las empresas transnacionales y de los países industrializados más importantes, como fuentes emisoras de mensajes vinculados al consumo y a la cultura de mercado. Quienes argumentan en favor de efectos diferenciados y heterogéneos destacan dinámicas de apropiación y modificación del mensaje y de sus símbolos en los niveles nacionales y subnacionales. Por otra parte, numerosos especialistas han tendido a resaltar la simultaneidad de procesos de diferenciación junto a los de homogeneización. En coincidencia con esta última línea argumentativa, en nuestro entender, la globalización pone en marcha mecanismos que actúan en ambas direcciones, retroalimentándose entre sí.

En las sociedades occidentales y occidentalizadas, la impresión de malestar se generaliza creando las bases de la demanda que impulsa la proliferación de prácticas y productos terapéuticos dirigidos tanto al tratamiento de las experiencias dolorosas 0 sufrientes -físicas o psíquicas-, como a alcanzar un mayor grado de bienestar y plenitud. Aunque no necesariamente impliquen enfermedad o padecimiento, estos estados inferiores a lo óptimo son escasamente tolerados.

En el escenario contemporáneo, la sensación de malestar y la impresión de insuficiencia emergen en la comparación con un ideal de bienestar asequible pregonado en los discursos sociales (Ehrenberg, 2000). La disposición anímica promovida en tales discursos ("moral alta", equilibrio emocional, sentido de vida, salud y diligencia) no es condescendiente en relación con las aflicciones de los sujetos, y estimula la necesidad de estar bien en todo momento, esto es: aun cuando las condiciones sean adversas y reclamen otros procesos. A nivel subjetivo, la exacerbación de este ideal promueve el registro de la "falta": falta de entusiasmo, de vitalidad, de juventud. Las carencias son generalmente identificadas por el propio agente, comparando sus estados habituales con los estándares de lo "normal" y lo "bueno" enaltecidos en las culturas.

De esta manera, la psicología se posiciona como uno de los núcleos principales de la globalización cultural, una fuente de modelos en torno de los cuales los individuos se organizan en todo el mundo. El discurso terapéutico ha llegado a constituirse como uno de los principales códigos con los cuales expresar, conformar y guiar al yo: "sea bajo la forma del análisis introspectivo, de un taller new age de 'mente-cuerpo' o de un programa de reafirmación personal, la 'terapia' ha logrado un nivel inusual de legitimidad cultural en una gran variedad de grupos sociales, instituciones y entornos culturales" (Illouz, 2010, p. 85).

Asociado con esta nueva responsabilidad sobre el sí mismo y el esfuerzo puesto en el autoconocimiento, los sujetos adquieren una nueva actitud frente a la enfermedad, y desafían las prescripciones médicas. En ese marco, los modelos de medicinas holísticas 
ofrecen versiones completas de la enfermedad que resultan a la postre más convincentes que el modelo biomédico: interpretan simultáneamente el malestar emocional y existencial conjuntamente con los desarreglos somáticos. Esta preferencia por modelos holísticos que admitan un nivel de comprensión de la enfermedad como consecuencia de un "estado del alma" va ganando terreno en la medida en que apunta a "estilos de vida" que también son considerados como fuente de numerosos males contemporáneos.

En el campo de la salud, el parámetro no es estar sano o enfermo sino "estar en forma". Si la salud/enfermedad era experimentada como "estado" (con un posible origen, desarrollo y fin), estar en forma carece de parámetros claros. Aunque "salud" y "estar en forma" se empleen como sinónimos y remitan a una mirada sobre el cuerpo, ambos conceptos pertenecen a órdenes discursivos distintos. "Salud" se refiere a un orden normativo que distingue lo normal de lo anormal, a un estado corporal y espiritual deseable para satisfacer las demandas del orden social. "Estar en forma" es indefinido, no delimitado, constatable a futuro. Siguiendo a Bauman: "significa tener un cuerpo flexible y adaptable, preparado para vivir sensaciones aún no experimentadas e imposibles de especificar por anticipado" (2007, p. 83).

Asimismo, esta concepción (de la salud como un estado de completo bienestar físico, mental y social) trae aparejado un efecto de normalización por el que ese estado completo de bienestar se halla siempre en desplazamiento, de modo que se genera un parámetro de salud inalcanzable. Bajo esta perspectiva se hace inteligible la configuración sociocultural de un modo de ser saludable y un imperativo de "salud perfecta". La salud deviene en un ideal y el cuidado personal para alcanzarla se torna una cuestión moral. Esta concepción comporta un entramado de prácticas sociales y biomédicas tendientes al mejoramiento y la optimización de la salud y la vida misma, entre las que pueden incluirse cuestiones tan disímiles como la alimentación saludable, las cirugías estéticas, el antiaging, la medicina biológica y genética, el fitness, la meditación, y las medicinas alternativas. Estas últimas incluyen terapias ligadas a la New Age, tales como la reflexología, el yoga, la terapia de vidas pasadas, el reiki, etc. Este tipo de prácticas pone en evidencia que la red de discursos sociales en torno al imperativo de "salud perfecta" conlleva efectos concretos de subjetivación.

Frente a la expansión y consumo masivo de estas culturas terapéuticas -en tanto amalgama de discursos, saberes legos y expertos, prácticas y creencias científicas y religiosas que conciben el malestar subjetivo y la dolencia física como sufrimiento inaceptable o sólo admisible en niveles muy bajos-, cabe preguntarse qué ocurre con los conocimientos ancestrales vinculados al cuidado de la salud, sobre todo en sociedades con culturas sanitarias ancestrales.

$\mathrm{Si}$ como señalamos al principio, el contacto entre las culturas produce constantemente hibridaciones, préstamos, apropiaciones selectivas de ciertos elementos de las culturas tanto hegemónicas como no hegemónicas, junto con rechazos selectivos de unas y otras, y teniendo en cuenta que las "maneras de curar" desempeñan un rol importante en los procesos de construcción identitaria y cohesión social de una población, creemos que indagar en sus representaciones y prácticas, puede permitirnos comprender las complejas articulaciones entre lo local y lo global. 
Rostros mestizos: una propuesta comunicacional para el estudio de itinerarios terapéuticos ancestrales en Latinoamérica

\section{CONCLUSIONES}

Reconocemos que las sociedades, particularmente en Latinoamérica, han desarrollado experiencias y sistematizado formas especiales de "conocer y saber" acerca de la salud y la enfermedad, que han ido configurando un conjunto de nociones y conocimientos formados en la práctica cotidiana y espontánea de las personas, hasta llegar a la práctica empírica que concentra y sistematiza la experiencia de la colectividad a lo largo del tiempo: la medicina tradicional. Coincidimos con numerosos investigadores que destacan el indudable valor cultural de este saber informal, que merece ser valorado y estudiado críticamente, en especial cuando puede tener un impacto sustantivo sobre la salud pública.

Frente a ello, hemos planteado la posibilidad de analizar las representaciones sobre la vigencia y circulación de saberes ancestrales, desde una mirada comunicacional. En este sentido, hemos puesto a consideración tres argumentos. El primero refiere al estudio de esta problemática bajo el arco teórico de la Comunicación y Salud, donde la "Salud intercultural" y la "Comunicación para el cambio social" aparecen como herramientas intelectuales que permiten establecer un diálogo respetuoso entre maneras de pensar cuerpo, salud y enfermedad en contextos de complejidad intercultural. Estas perspectivas abogan por la revalorización de las prácticas terapéuticas tradicionales, y hacen énfasis en una comunicación horizontal, como intercambio, como acción de compartir valores. Una metodología que consideramos adecuada para analizar la diversidad y abordar conceptos "otros" de salud y enfermedad.

El segundo argumento refiere a la posibilidad de pensar en los discursos en torno a los saberes tradicionales como parte del patrimonio cultural intangible de una población. Ello implica entender al patrimonio cultural a partir de los sentidos -diversos y muchas veces con versiones "en disputa"-, que les dan los actores sociales, considerando sus intersecciones con lo global y con otras expresiones culturales locales. Esto permite una comprensión integral de las diferentes formas de concebir los bienes culturales, tanto heredados desde un extenso pasado como resignificados en el presente.

El último argumento, se vincula a las formas híbridas que asume lo étnico tradicional frente a las condiciones del desarrollo socioeconómico y cultural capitalista. En nuestros días, la salud se define como un "estado de completo bienestar físico, mental y social", por lo que deviene en una categoría escurridiza que comporta elementos vinculados a la calidad y al estilo de vida. La enfermedad aparece como una etapa que exige redefinir nuestra vitalidad. Estas imágenes se integran con otras. La sumisión a ciertas normas de belleza producidas por la publicidad y la televisión, la necesidad de salvarse de la vejez aparentando una juventud artificial, todo ello configura un mercado que crea dependencias cada vez más amplias y arraigadas en todos los niveles de la población. En este contexto de expansión de las culturas terapéuticas, creemos relevante indagar en las representaciones acerca de las prácticas sanitarias tradicionales, a fin de reflexionar sobre los fenómenos -de mixtura, convivencia, yuxtaposición, invisibilización- que se producen en la articulación entre los saberes propios y "ajenos". 
Rostros mestizos: una propuesta comunicacional para el estudio de itinerarios terapéuticos ancestrales en Latinoamérica

Las culturas forman parte de procesos históricos vivientes, dinámicos y se transforman constantemente. Repensar sobre los discursos y narrativas en torno a los saberes terapéuticos locales, permite revelar uno de los rostros mestizos que produce el choque entre la resistencia cultural y los intentos de mundialización de la cultura.

\section{BIBLIOGRAFÍA}

Abad, L. (2005). El concepto de competencia cultural aplicado a los agentes y actores de cooperación con pueblos indígenas de América latina. En V. Bretón y A. López (coord.). Las ONGS en la reflexión antropológica sobre el desarrollo y viceversa. Perspectivas africanas y latinoamericanas (pp. 87-101). Sevilla: Fundación El Monte.

Alcalay, R. (1999). La comunicación para la salud en las universidades estadounidenses. Revista Panamericana de Salud Pública, 5(3), 192-196.

Almirón, A., Bertoncello, R. y Troncoso, C. (2006). Turismo, patrimonio y territorio: una discusión de sus relaciones a partir de casos de Argentina. Estudios y Perspectivas en Turismo, 15, 101-124.

Arévalo, J. (2004). La tradición, el patrimonio y la identidad. Revista de estudios extremeños, 60(3), 925-956.

Bauman, Z. (2007). Modernidad líquida. Buenos Aires: Fondo de Cultura Económica.

Baxeiras Divar, J. (2006). Salud intercultural. Relación de la medicina kallawaya con el sistema de salud pública en San Pedro de Curva. En G. Fernández Juárez (coord.) Salud e interculturalidad en América Latina: antropología de la salud y crítica Intercultural (pp. 271-288). Quito: Ediciones Abya-Yala.

Campos, R. (2004). Experiencias sobre salud intercultural en América Latina. En G. Fernández Juárez (Coord.), Salud e interculturalidad en América Latina. Perspectivas antropológicas (pp. 129-151). Quito: Abya-Yala.

Cuberli, M. y Araújo, L. (2015). Las prácticas de la comunicación y salud: intersecciones e intersticios. En M. Petracci (Coord.). La salud en la trama comunicacional contemporánea (pp. 21-33). Buenos Aires: Prometeo.

Ehrenberg, A. (2000). La fatiga de ser uno mismo. Buenos Aires: Nueva Visión.

Flores, J. (2011). Interculturalidad en salud y eficacia: algunas indicaciones de uso para ONGD's con proyectos en salud en América Latina. Nuevo Mundo, Mundos Nuevos. Recuperado de https://journals.openedition.org/nuevomundo/61232.

García Canclini, N. (1999). Los usos sociales del patrimonio cultural. En E. Aguilar (coord.). Patrimonio etnológico. Nuevas perspectivas de estudio (pp. 16-33). Andalucía: Consejería de Cultura. 
Gil García, F. (2011). Introducción al dossier "Salud y enfermedad en América Latina. Una perspectiva intercultural", Nuevo mundo, Mundos Nuevos. Recuperado de http://journals.openedition.org/nuevomundo/61781

Gumucio Dagron, A. (2011). Comunicación para el cambio social: clave del desarrollo participativo. Signo y Pensamiento, $X X X(58), 26-39$.

Illouz, E. (2010). La salvación del alma moderna. Buenos Aires: Katz.

Lacarrieu, M. y Pallini, V. (2001). La Gestión de Patrimonio(s) Intangible(s) en el Contexto de Políticas de la Cultura. En: Primeras Jornadas de Patrimonio Intangible. Memorias, identidades e Imaginarios Sociales (pp. 81-104). Buenos Aires: Comisión para la Preservación del Patrimonio Histórico Cultural de la Ciudad de Buenos Aires.

Martín, B. (2003). Nuevos turistas en busca de un nuevo producto: el patrimonio cultural. PASOS. Revista de turismo y patrimonio cultural, 1(2), 155-160.

Obregón, R. (2010). Un panorama de la investigación, teoría y práctica de la comunicación en salud. Folios, 23, 13-29.

Oyarce, A. (1998). Política intercultural en salud: elementos de una propuesta. En Memoria del Primer Encuentro Nacional Salud y Pueblos Indígenas: hacia una política Nacional Intercultural en Salud (p. 54-62). Washington: Organización Panamericana de la Salud.

Pardo, M. y E. Gómez (2003). Etnobotánica: aprovechamiento tradicional de plantas y patrimonio cultural. Anales Jardín Botánico de Madrid, 60(1), 171-182.

Pulido Fuentes, M. (2017). Una mirada desde la salud intercultural en programas de cooperación al desarrollo. Boletín Americanista, 1(74), 33-51.

Villaseñor, I. y E. Zolla (2012). Del Patrimonio cultural inmaterial o la patrimonialización de la cultura. Cultura y representaciones sociales, 6(12), 75-101. 